Revista Destaques Acadêmicos, Lajeado, v. 9, n. 2, 2017. ISSN 2176-3070

DOI: http://dx.doi.org/10.22410/issn.2176-3070.v9i2a2017.1399

www.univates.br/revistas

\title{
POLÍTICAS PÚBLICAS VOLTADAS PARA A INCLUSÃO SOCIAL DE SURDOS
}

\author{
Leandro Francisco Alves ${ }^{1}$, Marcelo Franco Leão ${ }^{2}$, Francisca Melo Agapito ${ }^{3}$
}

Resumo: Em nosso país muitas leis são criadas, porém poucas delas realmente são efetivadas, quase sempre por não atender de fato às necessidades reais da sociedade. A escola é um local onde todos cabem ou ao menos deveriam caber. Um aspecto abordado nesse estudo está relacionado ao atendimento às pessoas surdas nas escolas. É preciso considerar que os surdos, por grande parte da sociedade, não são vistos por suas potencialidades, mas pelas limitações impostas por sua condição. Dessa maneira, são enxergados apenas como pessoas deficientes e, portanto, incapazes, o que além de triste é inadmissível na contemporaneidade. Este estudo teve como objetivo provocar reflexão dos assistentes sociais sobre sua função social e aprofundar o conhecimento sobre os fundamentos das políticas públicas para inclusão de surdos. Trata-se de uma pesquisa básica, de cunho teórico, cuja abordagem é qualitativa. Sua realização ocorreu em 2014, o intuito da investigação foi descrever e explorar os aportes teóricos e a legislação vigente no país sobre a temática. No estudo é apresentada uma retrospectiva das políticas sociais brasileiras, algumas reflexões sobre a inclusão social do surdo, bem como as políticas públicas existentes no país em prol dessa inclusão e por fim é discutido sobre o papel do Assistente Social nessa situação. Espera-se que a compreensão das políticas públicas existentes para a inclusão dos surdos possa contribuir para a compreensão da importância desse atendimento, e de mais qualidade nos serviços que lhe são oferecidos.

Palavras-chave: Responsabilidade. Direito. Respeito.

1 Graduado em Serviço Social (UNOPAR). Graduação em Pedagogia (FACIBRA). Graduação em História (FPA). Pós-graduado em LIBRAS e em em Psicopedagogia com ênfase em Educação Inclusiva (FACIBRA). Professor da Universidade de Cuiabá (UNIC) Campus Tangará da Serra/MT.

2 Graduado em Química (UNISC) e em Física (UNEMAT). Pós-graduado em Orientação Educacional (Dom Alberto) e em Relações Raciais na Educação e na sociedade Brasileira (UFMT). Mestre em Ensino (UNIVATES). Doutorando em Educação em Ciências (UFRGS). Professor do IFMT Campus Confresa.

3 Graduada em Pedagogia (UDESC). Pós-graduada em em LIBRAS (FAPAF) e em Metodologia do Ensino Superior (UEMA). Mestra e doutoranda em Ensino (UNIVATES). Professora da UFMA. 


\section{INTRODUÇÃO}

A temática inclusão vem sendo amplamente estudada e debatida por pesquisadores na atualidade. Contudo, na maioria das vezes, as ações efetivas e as políticas públicas elaboradas para incluir todos na sociedade geralmente não atingem seus objetivos. Um exemplo disso é a inclusão de surdos nas escolas, pois mesmo havendo legislações específicas para esse atendimento, o que se percebe é a falta de profissionais capacitados para atender as pessoas com surdez.

No Brasil, segundo dados do último Censo (IBGE, 2010) são aproximadamente 5,7 milhões de brasileiros surdos ou que apresentam algum tipo de deficiência auditiva. De acordo com o Decreto $n^{\circ}$ 5.296/04, no capítulo, artigo $5^{\circ}$, pessoa com deficiência auditiva é aquela que tem "perda bilateral, parcial ou total, de quarenta e um decibéis $(\mathrm{dB})$ ou mais, aferida por audiograma nas frequências de $500 \mathrm{~Hz}, 1.000 \mathrm{~Hz}, 2.000 \mathrm{~Hz}$ e $3.000 \mathrm{~Hz}$ " (BRASIL, 2004).

Ainda referente ao campo conceitual, o Decreto $n^{\circ}$ 5.626/05 explica em seu capítulo I, artigo que pessoa surda àquela que "por ter perda auditiva, compreende e interage com o mundo por meio de experiências visuais, manifestando sua cultura principalmente pelo uso da Língua Brasileira de Sinais - LIBRAS" (BRASIL, 2005).

Nos estudos de Carvalho (1997, p. 13), é apontado que "Pessoas nascem com deficiências em todas as culturas, etnias, níveis socioeconômicos e sociais". O autor explica ainda que "[...] Em todos os tempos e épocas, sabe-se que pessoas nascem ou tornam-se portadoras de deficiência: cegas, surdas, com limitações intelectuais ou físicas".

A surdez pode ser entendida como a audição socialmente incapacitante. Ou seja, o surdo é incapaz de desenvolver a linguagem oral, consequentemente porque não consegue ouvir. No entanto, isso não o impede de se comunicar, haja vista, o mesmo possui a Língua Brasileira de Sinais (LIBRAS) como língua materna, que possibilita a sua comunicação em diferentes contextos (BRASIL, 2007).

A pessoa surda apresenta características e problemas que merecem uma análise mais profunda. Os fatores que determinam os problemas causados pela surdez são muitos e somente com uma avaliação bem ampla da realidade é possível perceber as diversas situações que acabam por originar tais problemáticas, acrescenta-se a isso as dificuldades que as mesmas enfrentam para poder se manter com dignidade.

A questão da surdez não pode ser observada como um fenômeno dos tempos modernos, pois ela sempre existiu, mas passava despercebida aos olhos das pessoas, ou pior ainda, excluíam os surdos por entender que estes seriam um problema para a sociedade. Segundo Godoi (2009), na Idade Média as pessoas com deficiência, inclusive auditiva, eram consideradas loucas, criminosas, ou ainda possuídas por demônios. Assim sendo, faziam parte 
da classe dos excluídos e deviam ser afastadas do convívio social, ou mesmo sacrificadas.

Infelizmente, nessa época, as pessoas que nasciam surdas, eram tratadas como loucas, algumas sendo torturadas ou submetidas a situações totalmente desumanas, como por exemplo, o oralismo, que foi uma abordagem educacional que tinha como objetivo obrigar os surdos a falar (SANTANA, 2007). E por não conseguirem avançar em muitos momentos nos treinos a que eram submetidos, eram tratados como doentes mentais e em algumas situações eram implantadas até mesmo, orelhas de animais com o intuito de estimular a audição.

Na atualidade, a situação se modificou. Os surdos, hoje, não são tratados como doentes mentais, contudo, ainda não recebem o respeito que merecem. Em diferentes contextos, temos pessoas ainda pensam e agem de forma preconceituosa e excludente, a exemplo, no mercado de trabalho ou até mesmo no ambiente escolar. Além disso, quando surdos são inseridos em uma escola, muitas vezes os próprios professores não sabem se comunicar por não entenderem sua língua.

Por serem pessoas dotadas de dignidade humana, independentemente de suas dificuldades ou deficiência, os surdos precisam ser respeitados e considerados como indivíduos de grande importância na estrutura social. Contudo, são muitos os desafios a serem superados. As famílias, por exemplo, tem sofrido grandes preocupações referentes à inclusão social. Soma-se a isso, $\mathrm{o}$ fato de que esta passou a ser uma entidade quase restrita em ações para incluir.

Outra dificuldade bastante recorrente é a falta da aceitação da família, quando ocorre o diagnóstico que um membro do grupo familiar é surdo. Situação que ocorre devido ao preconceito ainda muito difundido referente a esse assunto. Tal dificuldade é observada inclusive com famílias de alto poder aquisitivo, que mesmo dispondo de recursos para buscar serviços de atendimento profissional, acaba tendo dificuldade no que tange a convivência familiar.

Outro desafio a ser superado refere-se à inclusão de estudantes surdos, haja vista apesar desta ocorrer, o processo vem se dando de forma demasiadamente desorganizada. Um exemplo dessa situação é a falta de intérpretes de LIBRAS nas escolas, o que dificulta a compreensão entre o estudante surdo e professor, pois este profissional é o elo de comunicação entre estes sujeitos e quando não há comunicação, o entendimento entre ambas as partes fica prejudicado (QUADROS, 2004). Esta situação é muito preocupante, visto que, a própria constituição assegura que todos têm direito a educação.

A legislação de modo geral enfoca a importância da dignidade humana. O artigo $6^{\circ}$ da Constituição Federal (BRASIL, 1988), deixa claro que um dos direitos sociais conquistados e garantido é a educação e o trabalho, além de outros como moradia e a previdência social. Fato este que contribui e muito 
na hora de conceder algum benefício ou mesmo auxílio para o convívio e o fortalecimento do vínculo familiar.

Diante do exposto, o objetivo deste artigo é estimular a reflexão dos profissionais envolvidos nas questões sociais e aprofundar o conhecimento, assim como alguns fundamentos das políticas públicas para inclusão de surdos, para que seja possível identificar seus espaços, seus direitos, e fortalecer a convivência e os vínculos familiares, além de intensificar as políticas públicas sociais.

Este estudo teórico ocorreu durante o desenvolvimento do Trabalho de Conclusão de Curso de Bacharel em Serviço Social, o qual foi defendido em 2014. Configura-se como uma pesquisa básica de cunho bibliográfico, pois utilizou para sustentar as discussões alguns materiais teóricos já publicados (GIL, 2010). A pretensão foi analisar e apontar formas de fortalecer os vínculos, o convívio social da pessoa surda, além de entendê-la como sujeito consciente de sua identidade, bem como seu papel na sociedade e a atuação do Serviço Social neste seguimento.

Inicialmente, o estudo faz uma breve retrospectiva das políticas sociais brasileiras. Na sequência é discutido sobre a inclusão social do surdo, desde o seu início, mostrando as dificuldades enfrentadas até a atualidade. Também são apresentadas as políticas públicas existentes no país para a inclusão social de pessoas surdas e por fim é discutido o papel do Assistente Social na inclusão de surdos na sociedade.

\section{A REALIDADE DAS POLÍTICAS SOCIAIS BRASILEIRAS}

Por muito tempo no Brasil, os partidos políticos foram apreciados como agentes da participação política. Desde o começo da década de 1970 a mudança social encontra-se voltadas a esses partidos, principalmente os vanguardistas, não havendo neste período uma ação voltada aos interesses coletivas da sociedade.

Foi neste cenário de poucas ações que começaram a surgir as diferentes organizações não governamentais (ONG's), que passaram a desenvolver ações sociais voltadas aos interesses sociais, provocando profundas alterações na esfera da participação política. Foi neste período que os partidos brasileiros começaram a se organizar e passaram a ser considerados importantes instrumentos políticos-organizativos da classe trabalhadora (DURIGUETTO, 2007).

O autor acima mencionado ainda afirma que:

Entre as amplas expressões de mobilização e organização popular deste período, tiveram destaque às mobilizações promovidas pelos metalúrgicos do $\mathrm{ABC}$ paulista e a pluralidade de reivindicações pautadas pelo movimento feminista, movimento homossexual, 
movimento negro, além de diversos outros movimentos populares que emergiam naquele momento (DURIGUETTO, 2007, p. 70).

Em meados dos anos 90 foi um período da participação popular onde a consolidação da democracia se faz presente, uma das maiores conquistas que podemos considerar foi à elaboração e a implantação da Constituição Federal de 1988, um grande avanço referente aos direitos sociais e coletivos adquiridos por meio de movimentos sociais, abaixo-assinados, mobilizações, articulações nacionais e movimentos de pressão popular, para a inserção de leis no texto da Constituição Federal, que garantissem os direitos negados durante o regime militar. É por meio das transformações da sociedade da sociedade civil que surgiu a denominada sociedade política (SINGER, 2009).

Outro aspecto a ser considerado é que o processo de desenvolvimento do Estado está pautado no capitalismo, um modelo democrático criado para atender as necessidades burguesas e de consumo de produção da sociedade capitalista. Assim, o Estado fica responsável por garantir as condições de produção e reprodução das forças do capital, se fazendo simples diferenças sociais, as diferenças da vida privada (SINGER, 2009).

Em contraposição à postura deste sistema, não se pode deixar de registrar os trabalhadores que representam a força de trabalho e também a massa que ajuda na construção e na movimentação do capitalismo por meio do consumo abusivo (ENGELS, 1986). A partir da capacidade da juntura política é que se expandem as demandas do Serviço Social, em que a profissão passa a orientar a população para uma perspectiva dialética, buscando o desenvolvimento da prática institucional, se destacando na mediação entre o Estado e a sociedade civil, em busca dos avanços da organização dos movimentos sociais (SILVA, 2006).

Nesse sentido, o autor mencionando anteriormente aponta que:

O percurso do Serviço Social no Brasil, no período de 1964 a 1985, configura uma intensa movimentação dos assistentes sociais que repercute profundamente nas três dimensões constitutivas da profissão representada pela dimensão político-organizativa, pela dimensão acadêmica e, talvez com menor intensidade, pela dimensão da intervenção social profissional, no nível dos organismos da política social, das empresas privadas e dos movimentos sociais (SILVA, 2006, p. 42).

Nessa perspectiva, quase todas as ações eram reprimidas, o Serviço Social possuía uma ação interventiva na realidade social, visto que essa teoria tinha uma dimensão crítica do sistema capitalista, já que a profissão buscava uma nova proposta de formação. 
Esse momento pode ser nomeado como "Movimento de Reconceituação da Profissão ${ }^{4 "}$ que se voltava na perspectiva dialética de uma análise institucional, este movimento objetivava estimular os avanços e práticas institucionais. Este período de transição da profissão ocorreu no período do Estado novo, momento em que a categoria buscava alternativas para intervenção social diante das profundas desigualdades, opressões e explorações das relações entre capital e trabalho que a população estava inserida (FALEIROS, 1999).

A década de 1980 foi vista como um momento oportuno de transformação da sociedade civil, este período foi muito importante no traçado dos rumos técnicos, acadêmicos e políticos para o Serviço Social, pois foi a partir deste momento que se pôde elaborar um projeto profissional que, hoje aglutina grandes números de assistentes sociais no país (IAMAMOTO, 2009).

Sobre os aspectos anteriormente abordados, o autor enfoca ainda que:

A categoria dos assistentes sociais foi sendo questionada pela pratica política dos diferentes seguimentos da sociedade civil. E os assistentes sociais não ficaram a reboque desses acontecimentos. Ao contrário, tornaram-se um dos seus coautores, coparticipantes desse processo de lutas democráticas na sociedade brasileira. Encontra-se ai a base social de lutas da reorientação da profissão nos anos de 1980 (IAMAMOTO, 2009, p. 51).

Nos últimos tempos, o Serviço Social contraiu maior qualificação na sociedade brasileira; isso se deve também à implantação do código de ética do Assistente Social, a revisão da literatura e ao aumento significativo do acervo, além das alterações no ensino universitário e das pesquisas realizadas, reconhecidas por agências de fomento (IAMAMOTO, 2009). Leva-se em conta também as formas de representações em órgãos legitimados, a participação na discussão de políticas sociais públicas no campo das relações entre Estado e a Sociedade Civil.

A profissão vai se engajando e as lutas por direitos permanecem extremamente atual. Embora saibamos das dificuldades que este profissional encontra para ser reconhecido diante da sociedade capitalista, enfatizamos que é por meio de diversas tensões, expressões contraditórias e lutas que se apresentam os limites e potencialidades que são definidos no interior das lutas de classes (IAMAMOTO, 2009). Dessa maneira, os movimentos sociais ainda são os principais agentes no engajamento das lutas que norteiam as classes.

4 Movimento de Reconceituação da Profissão, constituiu-se numa expressão de ruptura com o Serviço Social tradicional e conservador; e na possibilidade de uma nova identidade profissional com ações voltadas às demandas da classe trabalhadora cujo eixo de sua "preocupação da situação particular para a relação geral particular", e passa a ter "uma visão política da interação e da intervenção" (FALEIROS, 1999, p. 133). 


\section{INCLUSÃO SOCIAL DOS SURDOS}

Os surdos são extremamente prejudicados em seu desenvolvimento, visto que, à medida que dão início ao aprendizado da LIBRAS, este ocorre constantemente de forma tardia, ocasionando nesse processo prejuízos imensuráveis devido as situações peculiares inerentes a estes sujeitos e a aquisição de sua língua materna (GOES, 1996). Muitas crianças com deficiência chegam à escola apresentando uma defasagem de idade importante, se comparadas às crianças ouvintes.

A LIBRAS é o meio de comunicação da pessoa surda, sua forma de manifestar o pensamento, emoções, além do desenvolvimento psicológico. O acesso a essa língua o mais cedo possível, é a grande possibilidade que esta tem de desenvolver-se integralmente. $\mathrm{O}$ surdo tem direito a um intérprete de LIBRAS, para que seja feita a tradução e interpretação de todo o conteúdo ministrado em sala de aula (BRASIL, 2007).

Segundo o Programa Nacional de Apoio à Educação de Surdos existem algumas características fundamentais para atuar como intérprete de LIBRAS (BRASIL, 2004). Conforme o documento, para realizar uma boa interpretação em LIBRAS, se faz necessário adquirir três habilidades distintas: habilidade linguística com termos do português, ter amplo conhecimento dos sinais da LIBRAS e da estrutura da Língua de Sinais, além de habilidade mental e motora.

$\mathrm{Na}$ atualidade, a inclusão de surdos se dá no campo da comunicação, da inclusão tecnológica e principalmente por meio da educação que insere o surdo na sociedade, utilizando-se de diversificadas alternativas de ensino que proporcionam a interação interpessoal (BRASIL, 2007). Nesse sentido, o Site Acessibilidade Brasil, oferece importantes ferramentas para ocorrer a inclusão, além de disponibilizar um dicionário Online da LIBRAS, tem o intuito de realizar a divulgação, a expansão e a capacitação das pessoas envolvidas, sejam estas surdas ou ouvintes. Segundo o site, o objetivo desse importante canal é proporcionar meios para ocorrer à comunicação entre pessoas surdas e ouvintes.

\section{POLÍTICAS PÚBLICAS PARA SURDOS EXISTENTES NO PAÍS: ALGUMAS CONSIDERAÇÕES}

A educação é, por excelência, essencial para potencializar o desenvolvimento sociocultural e econômico do Brasil, mas, acima de tudo, somente por meio dela é que as pessoas podem se desenvolver integralmente, seja intelectual, cultural, psíquica ou afetivamente. Uma considerável parte da população brasileira, infelizmente, está privada da educação escolar. Referente aos surdos, esse índice ainda é maior. Além disso, em âmbito nacional, o quadro histórico educacional privilegia principalmente as pessoas com condições sócio econômicas favoráveis, ou seja, nem todas as pessoas têm as mesmas oportunidades. 
Corroborando esse pensamento, Alencar (1985, p. 34) afirma que:

[...] crianças de nível socioeconômico baixo, com privação cultural, com ambiente físico pouco estimulado, com pouco contato materno e conforme o contexto cultural de suas famílias apresentam dificuldades no desenvolvimento social, da personalidade e das habilidades cognitivas, ocorrendo o fracasso na escola.

Em contrapartida, Costa (1984) afirma em seus estudos, que é evidente o bom rendimento escolar de estudantes pertencentes a classes econômicas mais favorecidas, ou seja, aquelas famílias mais estruturadas financeiramente proporcionam melhores condições de estudos do que aquelas menos favorecidas.

Os estudantes que apresentam rendimento maior são os que melhor se alimentam, possuem uma melhor moradia e, geralmente, os pais têm um nível educacional mais elevado, possuindo maior motivação para o processo de aprendizagem. Daí a importância de relatarmos sobre o impacto da família no rendimento acadêmico. É preciso pensar as Políticas Públicas no que tange às Políticas Educacionais como sendo um fator que merece investimentos para se combater a exclusão social.

Cabe aqui ressaltar que à sociedade e ao Estado decorre do dever constitucional elencado no caput do Art. 227 (BRASIL, 1988), que versa: É dever da família, da sociedade e do Estado assegurar à criança e ao adolescente, com absoluta prioridade, o direito à vida, à saúde, à alimentação, à educação, ao lazer, à profissionalização, à cultura, à dignidade, ao respeito, à liberdade, e à convivência familiar e comunitária, além de colocá-los a salvo de toda forma de negligência, discriminação, exploração, violência, crueldade e opressão.

Decreto $n^{0} 3.298 / 99$ que regulamenta a lei $n^{0} 7.853$, de 24 de outubro de 1989, dispõe sobre a Política Nacional para integração da Pessoa Portadora de Deficiência, consolida as normas de proteção, e da outras providências. A Lei Federal n 10.172 de 09 de Janeiro de 2001, aprova o Plano Nacional de Educação e dá outras providências.

É de suma importância a participação dos pais na Educação e também na exigência do cumprimento das Políticas Públicas existentes. No contexto da realidade brasileira é preciso encontrar métodos que auxiliem e que se enquadrem às nossas necessidades e possibilidades dos familiares de pessoas surdas.

Frente a essa realidade, torna-se salutar que sejam empreendidas políticas sociais sérias, que resolvam os problemas e todos os seus efeitos, até mesmo, os de ordem psicológica, que afetam as pessoas envolvidas. Isto se houver necessidade, como no caso da prole que sofre a discriminação social.

É de fundamental importância que se faça o possível para viabilizar estas regras, com o intuito de melhorar a qualidade de vida destas famílias que 
sofrem com a condição em que estão inseridas. E isso somente será possível, se os profissionais que são responsáveis pela execução das políticas públicas, forem pessoas qualificadas e determinadas a mudar esse conceito que a sociedade tem em relação às pessoas que estão envolvidas nas questões sociais existentes (GODOI, 2009).

As mudanças mencionadas anteriormente são essenciais, tanto na forma de administrar as políticas públicas, como nos aspectos referentes à tomada de consciência por parte dos governantes e das pessoas que elaboram estas leis, visto que, é necessário que se tenha uma visão diferente da realidade social em que estamos inseridos na contemporaneidade, principalmente devido as constantes mudanças que ocorrem no mundo.

Precisamos investir mais em constantes treinamentos, valorização dos profissionais que farão a intervenção direta com essa realidade, buscando com isso a satisfação, a motivação e o bem-estar de cada um. Estes procedimentos se tornam regras básicas em prol de um aperfeiçoamento da capacidade de competir do ser humano, e com isso contribuir para o crescimento pessoal, visando o bem comum, ou seja, a eficácia do trabalho junto aos indivíduos que necessitam dessa intervenção.

\section{O PAPEL DO ASSISTENTE SOCIAL NA INCLUSÃO DOS SURDOS}

A profissão "Serviço Social" é conhecida por realizar um trabalho desenvolvido na coletividade, sua materialidade acontece na concretização de um processo de trabalho que tem como principal meta, o enfrentamento das inúmeras expressões da questão social ${ }^{5}$ (MARTINELLI, 2009).

A respeito do desenvolvimento do trabalho do Assistente Social, é indubitável ressaltar que este não exerce sua função de modo segregado, o laboro em conjunto faz parte de seu papel. Acerca deste aspecto Imamamoto (2004) explica que:

[...] O Assistente Social não realiza seu trabalho isoladamente, mas como parte de um trabalho combinado ou de um trabalhador coletivo que forma uma grande equipe de trabalho. Sua inserção na esfera do trabalho é parte de um conjunto de especialidades que são acionadas conjuntamente para a realização dos fins das instituições empregadoras, sejam empresas ou instituições governamentais (IMAMAMOTO, 2004. p. 65-64).

5 A questão social é uma questão estrutural do capitalismo e circunscreve um terreno de disputas, pois diz respeito à desigualdade econômica, política e social entre as classes na sociedade capitalista, envolvendo a luta pelo usufruto de bens e serviços socialmente construídos, por direitos sociais e pela cidadania (YASBEK, 2009, p.110). 
A atuação profissional do Assistente Social é focada na intervenção, configurando-se como um complexo processo marcado pelos distintos espaços sócio ocupacionais em que estes se inserem nas relações presentes na sociedade (YASBEK, 2009). Esses profissionais para atuarem no seu cotidiano devem apresentar um grau de experiência que deve estar atrelado ao seu período de estudos, realizados durante o estágio supervisionado e orientado por um profissional da área, neste período ele já pode adquirir um pouco de experiência a qual ele deverá expor em seu currículo.

Para que este profissional consiga desenvolver um bom trabalho é necessário que ele tenha uma postura ética e criativa que ultrapasse as rotinas institucionais, buscando interpretar as mudanças sociais nas suas mais diversas configurações, para que seja possível realizar um trabalho de formação, transformação e conscientização das famílias atendidas (IAMAMOTO, 2009).

Nesse sentido, o Assistente Social precisa atuar segundo o autor supracitado, por meio das políticas sociais, de maneira a desenvolver uma ação de cunho sócio educativo, possibilitando a ampliação e a garantia de direitos dos indivíduos marginalizados e subalternizados da sociedade, já que estes são vítimas das ações e condições impostas pelo capitalismo.

O profissional inserido nestes espaços sócio ocupacionais assume o compromisso pelo desenvolvimento das políticas públicas, enquanto ambiente democrático de direitos e promove ações de combate ao enfrentamento da pobreza, visando lutar contra o desmanche de direitos e construir parâmetros capazes de deter a privatização do público e garantir a hegemonia das classes trabalhadoras (YASBEK, 2009).

É de fundamental importância para o futuro profissional do Serviço Social, que este tenha em mente que o foco na família não é algo novo, mas que na verdade, ele está presente em vários documentos nacionais e internacionais, entre eles a Declaração dos Direitos Humanos da ONU (1948), a Constituição Federal do Brasil (1988), o Estatuto da Criança e do Adolescente (1990), o Estatuto do Idoso (2003), dentre outros.

Mesmo sabendo que as leis existem, é preciso interromper o ciclo de transmissão Inter geracional da pobreza, e focar nas questões mais subjetivas que envolvem o contexto familiar, de forma mais ampla e também para que todos possam ter uma educação de qualidade.

No campo das políticas públicas, na área da assistência social, o Plano Nacional de Assistência Social (PNAS) traz em suas prioridades ações junto à família que são tidas como o núcleo primeiro de apoio. Já o Sistema Único de Assistência Social (SUAS) se constitui na regulação e organização do que encontramos na PNAS, através de uma gestão descentralizada (VASCONCELOS; MORGADO, 2005).

Um dos norteadores fundamentais do Serviço Social é a proteção social, que deve estar em harmonia com as garantias legais dos cidadãos brasileiros. 
Seu objetivo é proteger o cidadão e sua família. Assim, é necessário que se amplie as garantias legais e consequentemente a oferta de apoio que permitirá que essa proteção se torne real (IAMAMOTO, 2009).

Conforme as propostas do SUAS, são dois os tipos de proteção para a família e os indivíduos: proteção social básica, que pressupõe ações de prevenção que fortaleçam as famílias fragilizadas por diversas razões; proteção social especial, que deve ser acionada em situações mais graves, nas quais a exclusão e a violação de direitos já se instalaram. Sendo assim, a família deve exercer o principal papel na formação social do indivíduo, ela passa a ser vista como objeto de intervenção, da ajuda humanitária e da produção de saberes.

A entrada de um programa de assistência social em uma família ou domicílio cria uma situação clara de ambiguidade e conflitos. Por um lado, pode representar apoio, acesso a bens, benefícios e serviços, por outro é uma invasão na intimidade da esfera privada, cerceando a liberdade e a autonomia das pessoas, com sérios riscos de normatização social e fortes componentes culturais (VASCONCELOS; MORGADO, 2005, p. 38).

Pelo exposto, é possível perceber que na esfera do direito, essas leis existem e são para todos os indivíduos envolvidos em questões sociais. Contudo, no cotidiano se vivencia uma situação bem diferente, a importância em relação ao grande potencial da família é minimizada enquanto espaço de proteção e de vivência social, quando esta não é apoiada e fortalecida em suas necessidades básicas. Com isso há um descontentamento ao se perceber que as usuais definições de apoio utilizadas nas políticas públicas sobre essa temática, estão muito negligentes e falhas por não possuírem pessoas empenhadas em executar seus papeis de forma coerente.

E com a análise da temática, fica claro que os desafios que pessoas surdas ainda enfrentam são enormes. Primeiro por não serem reconhecidas na sociedade como cidadãos de direitos, nos diversos contextos em que estão inseridos, segundo, por não conseguirem vaga no mercado de trabalho, devido à falta de oportunidades e ao preconceito referente a sua condição.

Enfatizamos ainda a perspectiva educacional, pois esta, que deveria ser de qualidade, é caracterizada quase sempre pelo despreparo tanto dos profissionais, como da própria instituição educativa, quando os surdos adentram nesses espaços necessitando de um profissional intérprete de LIBRAS altamente qualificado e preparado para atender e suprir suas expectativas (BRASIL, 2007).

É necessário também, atentar para oferta de inserção no mercado de trabalho para os surdos chefes de família, tendo em vista que, para eles é uma necessidade de sobrevivência, que vai muito além de aspectos de realização profissional. 
Portanto, a inclusão nas escolas é um grande desafio, aceitar o ingresso e a permanência do estudante surdo no ambiente escolar e tratá-lo de maneira igualitária é emergencial, visto que o princípio fundamental da escola inclusiva é que todos os alunos sempre que possível aprendam juntos independente de suas dificuldades ou diferenças (BRASIL, 2004).

\section{CONSIDERAÇÕES FINAIS}

Com a realização desse estudo foi possível constatar que o trabalho do Assistente Social é muito importante para a efetivação de políticas voltadas para a inclusão de surdos. Essa profissão visa garantir a mediação das políticas sociais para a população que dela necessita. O Assistente Social com seus instrumentos de atuação poderá identificar esta demanda exercendo um trabalho sério e comprometido.

Espera-se que em um futuro breve, a valorização das pessoas surdas ocorra efetivamente, visto que estas já perderam muito no decorrer do processo histórico em que estiveram imersas. A segregação da sociedade e da escola comum durante muitos anos, trouxe perdas irreparáveis. Até as próprias escolas especializadas não deixam de ser uma forma de exclusão, pois o convívio social é fundamental para o desenvolvimento humano.

Fica evidente na contemporaneidade, a necessidade de ocorrer à inclusão de surdos, não somente na escola, mas na sociedade como um todo. Assim, é importante a atuação do Assistente Social nessa interlocução entre a família e a escola, entre as pessoas surdas e os profissionais especializados para seu atendimento. Além disso, é necessário que as políticas públicas perpassem o papel e sejam cumpridas de forma corretas e dignas no atendimento a todos, sem distinção.

\section{REFERÊNCIAS:}

ALENCAR, E. M. L. S. A Criança na Família e na Sociedade. Petrópolis, Vozes, 1985.

AMARAL, L. A. Conhecendo a Deficiência em Companhia de Hércules. São Paulo. Robe Editorial. 1995.

BRASIL. Constituição da República Federativa do Brasil: promulgada em 5 de outubro de 1988. Brasília: Senado Federal, 1988.

BRASIL. Lei Federal 10.436, 2012. Dispõe sobre a Língua Brasileira de Sinais - LIBRAS E DÁ OUTRAS PROVIDÊNCIAS. Disponível em: <http:/ /www.planalto.gov.br/ ccivil_03/leis >. Acesso em 05 Fevereiro 2014.

BRASIL. O Tradutor e Intérprete de Língua Brasileira de Sinais e Língua

Portuguesa. Secretaria de Educação Especial; Programa Nacional de Apoio à 
Educação de Surdos. Disponível em: <portal.mec.gov.br/seesp/arquivos/pdf/ tradutorLIBRAS>. Brasília: MEC; SEESP, 2004. Acesso em 18/01/2014.

BRASIL. Decreto n 5.296/2004. Regulamenta as Leis nos $^{\text {s }} 10.048$, de 8 de novembro de 2000, que dá prioridade de atendimento às pessoas que especifica, e 10.098, de 19 de dezembro de 2000, que estabelece normas gerais e critérios básicos para a promoção da acessibilidade das pessoas portadoras de deficiência ou com mobilidade reduzida, e dá outras providências. Disponível em: <http:/ /www.planalto.gov.br/ccivil_03/_ ato2004-2006/2004/decreto/d5296.htm>. Acesso em 22/02/2014.

BRASIL. Decreto $\mathbf{n}^{\mathbf{0}} \mathbf{5 . 6 2 6}$, de 22 de dezembro de 2005. Regulamenta a Lei $\mathrm{n}^{\mathrm{o}} \mathbf{1 0 . 4 3 6}$, de 24 de abril de 2002, que dispõe sobre a Língua Brasileira de Sinais - LIBRAS, e o art. 18 da Lei no 10.098, de 19 de dezembro de 2000. Brasília, 2005. Disponível em: <http:// www.planalto.gov.br/ccivil_03/_ato2004-2006/2005/decreto/d5626.htm>. Acesso em 22/02/2014.

BRASIL. O Tradutor e intérprete de Língua Brasileira de Sinais e Língua

Portuguesa/ Secretaria de Educação Especial. Disponível em: <portal.mec.gov.br/ seesp/arquivos/pdf/direitoaeducacao>. Brasília: MEC; SEESP, 2007. $2^{\text {a }}$ Ed. Acesso em $22 / 02 / 2014$.

CARVALHO, E. N. S. Educação especial: deficiência mental Brasília: MEC / SEESP,1997.

COSTA, M. Rendimento Escolar no Brasil e a Experiência de Outros Países. São Paulo, Loyola, 1990.

DURIGUETTO, M. L. Sociedade civil e democracia: um debate necessário. São Paulo: Cortez, 2007.

ENGELS, F. A origem da família, da propriedade privada e do Estado. 3. ed. São Paulo: Global, 1986.

FALEIROS, V. de P. Desafios do Serviço Social na era da globalização. In: Serviço Social e Sociedade ${ }^{\circ}{ }^{\circ}$ 61. São Paulo: Cortez, 1999.

GIL, Antônio Carlos. Como elaborar projetos de pesquisa. 5. ed. São Paulo: Atlas, 2010.

GODOI, S. Políticas sociais II: Serviço Social. São Paulo: Pearson Education do Brasil, 2009.

IAMAMOTO. M. V. O Serviço Social na cena contemporânea. In: Serviço Social: direitos sociais e competências profissionais. Brasília: CEFESS/ABEPSS, 2009.

IBGE. Síntese de indicadores sociais: uma análise das condições de vida da população brasileira 2010. Rio de Janeiro: IBGE, 2010. 
MARTINELLI, M. L. Sentido e direcionalidade da ação profissional: Projeto ético Político em Serviço Social. n: A prática profissional do Assistente Social. 2009.

QUADROS. Ronice, Muller de. O tradutor e intérprete de língua brasileira de sinais e língua portuguesa / Secretaria de Educação Especial; Programa Nacional de Apoio à Educação de Surdos - Brasília : MEC ; SEESP, 2004.

SANTANA, Ana Paula. Surdez e linguagem: aspectos e implicações neurolinguísticas. São Paulo: Plexus, 2007.

SILVA, J. F. S. O Serviço Social e o popular: resgate teórico- metodológico do projeto profissional de ruptura. São Paulo: Cortez, 2006.

SINGER, A. Raízes sociais e ideológicas do lulismo. In: Novos Estudos n. 85. São Paulo: CEBRAP, 2009.

VASCONCELOS, E.; MORGADO, R. Proposta Conceitual do PAIF. Subsídios analíticos e metodológicos na lógica do SUAS e do PAIF/RJ. Rio de Janeiro: Governo do Estado do Rio de Janeiro/ Secretaria de Estado da Família e da Assistência Social, 2005.

YAZBEK, M. C. O Serviço Social e a Construção dos direitos sociais. In: A prática Profissional do Assistente Social. V.1, São Paulo: Veras Editora, 2009. 